\title{
The Electronic Learning System as a Means of Forming Professional Competencies among University Students
}

\author{
Ekaterina I. Zagrebina ${ }^{1}$, Zemfira G. Sharafetdinova ${ }^{2}$, Irina V. lushchik ${ }^{3}$, Svetlana M. Konyushenko ${ }^{4}$, Natalya V. \\ Ermoshina $^{5}$, Elena Y. Kosyakova ${ }^{5} \&$ Gulnaz S. Ashrafullina ${ }^{6}$ \\ ${ }^{1}$ Kazan National Research Technical University named after A. N. Tupolev, Kazan, Russia \\ ${ }^{2}$ Naberezhnye Chelny Institute of Social-Pedagogical Technologies and Resources, Naberezhnye Chelny, Russia \\ ${ }^{3}$ Moscow University named by S.Y. Witte, Moscow, Russia \\ ${ }^{4}$ Immanuel Kant Baltic Federal University, Kaliningrad, Russia \\ ${ }^{5}$ Chuvash State Pedagogical University named after I. Y. Yakovlev, Cheboksary, Russia \\ ${ }^{6}$ Kazan (Volga region) Federal University, Kazan, Russia \\ Correspondence: Ekaterina I. Zagrebina, Kazan National Research Technical University named after A.N. \\ Tupolev, 420111, K.Marks Street, 10, Kazan, Russia. E-mail: solo73@inbox.ru
}

\author{
Received: April 16, 2015 Accepted: April 26, 2015 Online Published: May 28, 2015 \\ doi:10.5539/jsd.v8n3p178 URL: http://dx.doi.org/10.5539/jsd.v8n3p178
}

\begin{abstract}
The purpose of this article is aimed at the development of pedagogical tools and methods of forming students' competencies in the course of higher education. The submitted paper presents the potential of information technology in forming professional competencies of the university students providing the students' classroom and individual organization. The grounds for the presented paper have become the ideas of competence-based approach, the system of modern didactic principles that intensify the students' learning and cognitive activities. The article describes the structure of modern e-learning system that satisfies the federal state educational standards and contributes to the students' professional competencies. This article is intended for the educators, researchers, heads of educational institutions engaged in the development of academic syllabi and pedagogical tools to provide university students with professional competencies.
\end{abstract}

Keywords: higher education, professional competencies, pedagogical tools, information technologies, e-learning system

\section{Introduction}

\subsection{Background}

The principle objective of modern higher education is to educate a qualified professional (a bachelor, master, post-graduate) ready to work and grow professionally, have social and occupational mobility, able to adapt to changing external conditions (Azarov, 2008; Prokofeva, 2012; Frolov, 2004). A competence characterizes the specificity of professional work and the quality of education of a modern university graduate. A significant element of competence is the experience - the integration of actions, methods and techniques in solving various problems achieved by the human into one unity. The professional competencies require continuous renewal and growth in professional knowledge, acquiring new information to successfully solve professional challenges. For the first time the education raises the question of continuity of the competence development according to the education levels, requires consideration of the specific competencies for every degree program.

The competencies are the result of higher education and are determined by its ability and readiness to accomplish professional and social activities in the selected subject area. In addition, the current socio-economic and socio-cultural conditions and transition to modern educational standards require competent professionals able to navigate in the ever-changing information flow, to think independently and creatively. Nowadays, this is impossible without information technology education in the education process. Using simulation computer games, geoinformation technology, e-learning systems allow to upgrade and intensify the process of environmental education. 


\subsection{Status of a Problem}

The modern conditions of competence-based paradigm require the development of pedagogical tools and methods to form the students' professional competencies in terms of higher vocational education.

The educational modes are significantly changing, there is a shift towards $t$ information-education technologies providing broad educational, pedagogical and activity opportunities. The issue of assessing the activity-related characteristics of the learning process and personal students' qualities is becoming more important. Therefore, there is a need to develop educational tools and methods of forming students' competencies in the course of higher vocational education (Ephraim, 2010).

The analysis of scientific literature shows that the problem of forming professional competencies attracts attention (Baydenko, 2004; Zimnya, 2006; Mukhametzyanova, 2010; Novikov, 2006; Subetto, 2000, Hutorskoy, 2003; Zeer, 2005). The information education technologies are regarded as a means and methods of arranging, transferring and providing information to students using a computer as a dynamic means of supporting the education process that radically changes the system of teaching methods (Isaev, 2008; Kirilova, 2008; Krechetnikov, 2002; Robert, 1994; Trainev, 2006). The educational process becomes more efficient due to implementation of didactic opportunities and enhancing teaching and learning activities, it becomes more interesting and interactive. In addition, it allows to include multiple channels of information perceiving which certainly improves the quality of students' knowledge.

\subsection{The Research Hypothesis}

The objective need in forming professional competencies among the university students determines the search for the technologies, methods and tools to provide pedagogical support of educational activities. The development of a universal educational technology aimed at forming professional and general cultural competencies in higher school using the achievements of computer and information technologies determines the scope of this study.

\section{Materials and Methods}

\subsection{Objectives of the Study}

We have identified the following research objectives: 1) to determine the possibilities of using information technologies in university education. 2) to rationalize the universal structure and develop the syllabus of the e-learning system 3) to introduce into the educational process and verify the effectiveness of the e-learning system in the process of training the university students.

\subsection{Theoretical and Empirical Methods}

To test the hypotheses of the study we have used theoretical (study and systematic analysis of the national and foreign philosophical, pedagogical, psychological and methodological literature in the field of environmental education, specification and synthesis, the regulations study, modeling and design of the learning process); empirical (pedagogical experiment, the analysis of curricula and programs, monitoring academic activities, developing an e-learning system for the environment - a study manual, questioning, testing, statistical analysis of the study results and their graphical representation) methods.

\subsection{The Basis of the Research}

The experiment was carried out at the Kazan National Research Technological University named after A.N. Tupolev - (KAI) from 2006 to 2013 . The experiment included 28 student groups of the $3 \mathrm{~d}$ and $4^{\text {th }}$ courses (a total of 668 students).

\subsection{The Rationale for Using the E-Learning System in the University Educational Process}

One of the urgent issues of education is the pedagogical process organization which could not only serve as the basis for the expansion of knowledge about the world but also could contribute to the development of axiological, intellectual, cultural and creative potential of the students.

The central challenge facing today's pedagogical science is the problem of improving the syllabus of vocational training especially in technical universities. It is connected to the rapid development of techniques and technologies, information methods and means, a need to develop a teaching system that would allow to develop along with the basic knowledge the ability to adapt quickly in a professional domain. The existing socio-economic and socio-cultural conditions require educating the professional and competent specialists able to navigate in the ever-changing flow of information, to think independently and creatively. Nowadays, it is impossible without students' acquiring knowledge and skills of using information technologies in the future 
professional activity.

A graduate from the university should acquire new knowledge, skills of information search, analysis, synthesis, using this knowledge in their professional activities. Undoubtedly, the training based on information education technologies contributes more to such development.

The information education technologies are the tools and methods of compiling and conveying information to the student using computer as a new, dynamically developing means of supporting the educational process that radically changes the system of forms and methods of education (Levina, 2012).

The information education technologies are inherently the system of teaching methods which provide optimal and effective perception, learning and using the academic information interactively. The software for educational purposes is the main component of information technology, therefore talking about the use of information technologies in education most often they mean this particular component. The possibilities of the information education technologies available to teacher allow for information- educational interaction between the teacher and the students online. This significantly facilitates the information exchange and the student becomes an information source and, alternately, a receiver.

In general, the information education technologies can be considered a subject of study, a means of communication and a teaching tool. All these areas can be demanded by education transforming the individual learning activities, modeling the activities of the specialist.

\section{Results}

\subsection{The Definition of the E-Learning System}

The education in the computer environment is not just the process of receiving new information. It is intellectual development, mastering other ways of thinking, expressing the ideas with new tools. In this connection there is a problem of creating high-quality training facilities, in particular, the e -learning methodical complexes and manuals. This is the information base of new generation which combines the advantages of traditional textbooks and possibilities of computer technology.

The e-learning system is a multi-purpose educational software system that ensures the continuity and completeness of the learning process, provides theoretic material, arranges training and achievement control, as well as information seeking, mathematical and simulation modeling with computer visualization.

The applicability of electronic-learning systems in the educational process is obvious, they allow to increase the level of implementation of the traditional didactic requirements. In comparison with textbooks their advantage becomes apparent since the e-learning systems allow for: automation and intensification of academic work (while designing teaching systems, getting ready for classes, selecting the educational material, developing the manuals); implementation of role-playing (business games, exercise, control and testing); machine simulation of real objects (systems) with artistic representation (visualization) of the dynamic results of simulation modeling; using hypertext and multimedia presentation of information; providing work comfort by creating a user-friendly interface; simplicity of storing bulk information.

To make the e -learning system an effective means of the educational process it should be built within the following provisions: the psychological and pedagogical requirements for the teaching devices are the basis of its development; the following provision should be taken into account: the individual characteristics of the students, their level of development, professional course in education, their health status, etc.; it is necessary to ensure the integration of interdisciplinary connections and continuity of the material; to establish a common approach to the selection of illustrative material, to develop an ergonomic design of the electronic system.

\subsection{The Structure of the of E-Training System Syllabus to Form the Professional Competencies among the Students}

To study the structure of the e-learning system it is necessary to identify its components and connections between them taking into account the features of hardware, software, and pedagogical support.

Concerning the e-learning system we can also regard the texts and extra-textual components as the most important particular structural systems (Fig. 1). 


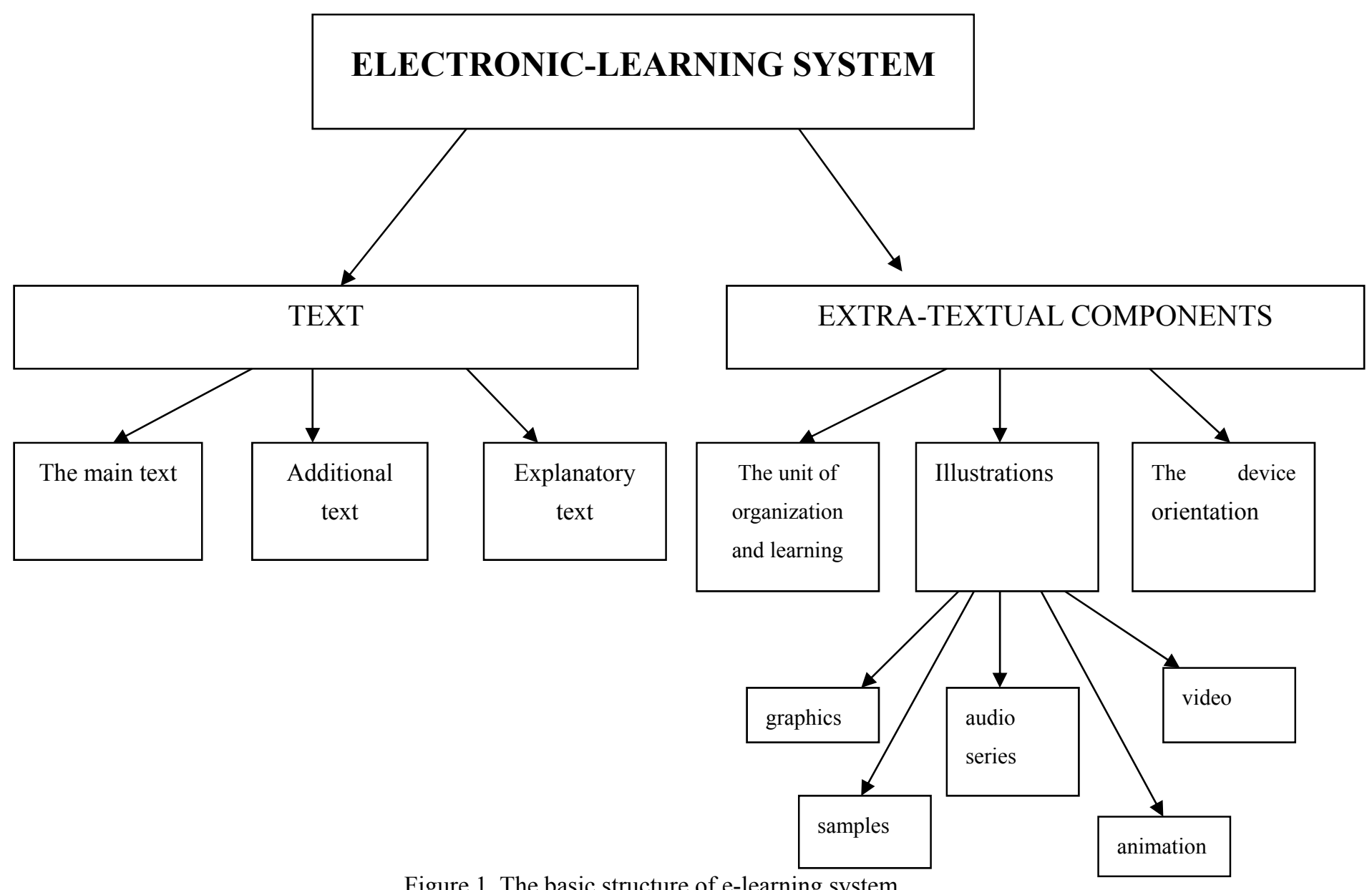

Figure 1. The basic structure of e-learning system

The system of extra-textual components becomes foremost and the texts begin to play a supporting role, explain the content of some extra-textual components. This shift in roles is limited with the computer possibilities and particularly the multimedia systems provide a variety of more expressive means than the text. The multimedia technology provides information not only in the form of texts, but also in the form of three-dimensional graphics, sound, video, animation, thus providing an ostensive and convincing explanation of the basic, fundamental, the most difficult moments of the teaching material.

The device of focusing the e-learning system intends to provide fast access to necessary information (eg., by keywords) to reflect the content of the material (hierarchical drop-down menus), to provide context-sensitive help, etc. The device of learning organization provides multiple individual learning tasks and their checkout that is completely impossible in the textbook. The rational methods of user interface can greatly expand the capabilities of the device orientation.

Another kind of information education technologies is various test systems. In general with tests introduction the pedagogy has obtained a possibility to use accurate statistical methods for evaluating the educational environment efficiency allowing to judge objectively the quality of its design. A test check contributes to the improvement of methods, techniques, procedures of teaching thus allowing to estimate their efficiency through the objective criteria (Moiseeva, 1996).

The computer technologies here have a greater potential: one program often combines several modes (education, training, monitoring). Using tests in e -learning systems allows students to independently observe gaps in their knowledge. This suggests a significant teaching potential of tests, practical implementation of the principle of unity and interrelation of education and control, an individual approach in education.

\subsection{Designing an E-Learning System}

In the course of this research we have developed a structure of the e-learning system "Ecology" for the students of technical universities (Fig. 2), and later the e -learning system itself. 
The e -learning system "Ecology" consists of three major modules - a substantive (includes basic and advanced level), practical (includes laboratory work in ecology, calculation tasks, simulation computer games) and reference (includes a glossary, legal framework, additional literature, an operation guide for working with e-learning system).

The particularity of the submitted e-learning system "Ecology" is a two-tier structure of environmental science teaching. The first (basic) level consists of 7 chapters and is designed for the students of all courses of technical universities studying this subject. The second (advanced) level consists of 12 chapters and is designed for the students of such specialties as "Safety in Technosphere", "Protection in emergency situations", for whom the ecology is a major.

Every chapter of both levels of the e-learning system "Ecology" ends with a formative assessment which can be used by students for self-examination, and by the teacher for intermediate knowledge assessment during the entire course of study. Every level ends with the summative assessment over the course that allows for total knowledge control.

A distinctive feature of the e-learning system "Ecology" is that to study the advanced level becomes possible only after passing $100 \%$ of pre-assessment of every chapter aimed at identifying the gaps in basic knowledge in ecology which appeared while studying the first chapter. To help the student who has failed at the first level the e-learning system offers to return to the underexplored material through the reference to the necessary chapter of basic level.

To form the professional skills which constitute the basis of professional competencies we have included in the e -learning system "Ecology" a complex of professionally-oriented tasks concerning atmosphere and hydrosphere pollution (eg, calculation of airborne discharge, the required degree of waste water purification). While making calculations it is possible to use the theory of e-learning system and special methodical material containing all the necessary formulas and table values required to solve the tasks.

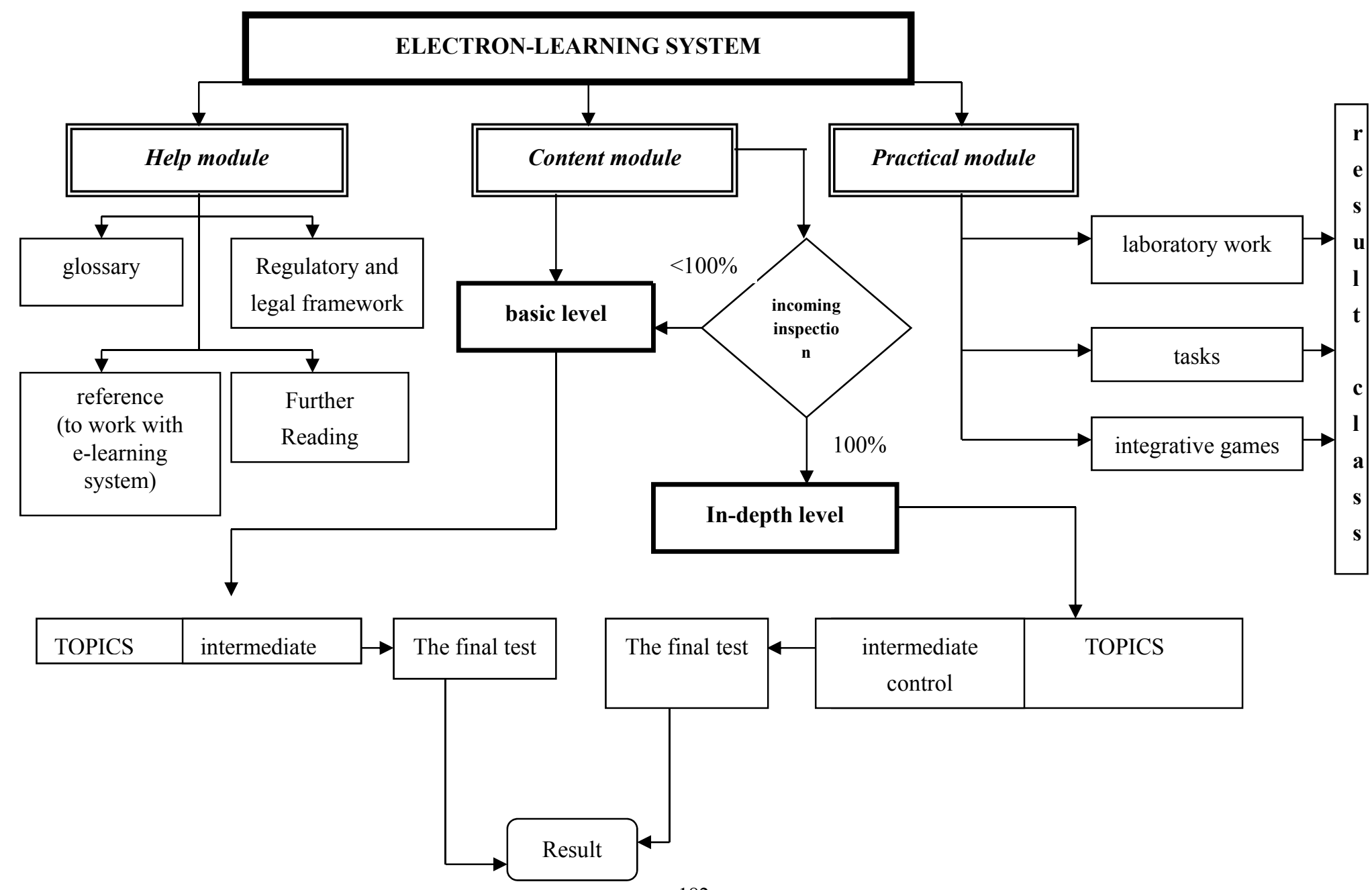




\subsection{The Effectiveness of Implementing the E-Learning System into the Higher Vocational Education}

To prove the effectiveness of using the developed e-learning system "Ecology" in the process of environmental education we have carried out an experiment where we have made a comparative analysis of formation of professional and general cultural competencies among the students studying "Ecology". The pedagogical experiment included control and experimental groups. The students of the control groups were taught according to the traditional program (lectures) and the experimental group were trained with the help of the e-learning system "Ecology" (Table 1).

The experiment was carried out at the Kazan National Research Technical University named after A.N. Tupolev (KAI).

Table 1. The results of the comparative analysis of professional and general cultural competence formation in the process of studying "Ecology"

\begin{tabular}{lccc}
\hline Competences & low level & average level & high level \\
\hline Professional competence (experimental group EG) & $17 \%$ & $63 \%$ & $21 \%$ \\
Professional competence (control group CG) & $31 \%$ & $47 \%$ & $12 \%$ \\
General cultural competence (experimental group EG) & $5 \%$ & $59 \%$ & $36 \%$ \\
General cultural competence (control group CG) & $12 \%$ & $71 \%$ & $17 \%$ \\
\hline
\end{tabular}

The analysis of the results showed the need to focus the e-learning system on achieving certain goals and outcomes. It is recommended to structure the educational material in accordance with the program and then select the appropriate forms, methods and teaching aids. In addition, while selecting and implementing information technology into the educational process we should take into account the specifics of the teaching material, the students membership, their age and level of education.

\section{Discussions}

The information education technologies are the tools and methods of compilation, transfer and provision of information to the student using the computer as a dynamic means of supporting the educational process that radically changes the system of education forms and methods. (Dereshko, 2006).

The possibility of using them in the university education is determined by the fact that they allow to:

- Model (and, consequently, forecast) professional situations;

- Model the processes and phenomena inaccessible to direct perception;

- Show (and then calculate) the parameters of phenomena and processes;

- Interactively manage the production (physical, chemical, other) processes.

\section{Conclusions}

The manifestation of professional competencies requires constant updating and growth of professional knowledge, learning new information to successfully solve professional challenges in a given time and under present conditions. Without the basics of information technology, the aspects of their application in professional activity and, consequently, without the educational process built on education information technology it is impossible today to get a qualified, mobile and competent specialist.

The introduction of information technologies into university vocational education significantly expands educational opportunities and provides efficient development of professional competencies.

\section{Acknowledgments}

The authors thank all participants of this study for their kind cooperation.

\section{References}

Azarov, R. N. (2008). Designing competence-oriented and competitive basic educational programs of HPE implementing. Publishing House «Guidelines», 81.

Baydenko, V. I. (2004). Competence in vocational training. Journal of Higher education in Russia, 11, 4.

Dereshko, B. J. (2006). Classification of information and communication technologies and their educational use 
in the classroom of the university. Journal Telecommunications and education, 1, 125.

Ephraim, N. F. (2010). Approaches to the evaluation of competencies in higher education. Textbook. Journal Research Center problem the quality of training, 216.

Frolov, O. V. (2004). Competence model as a basis for assessing the quality of specialist training. Publishing House «Higher education today», 8, 87.

Hutorskoy, A. V. (2003). Key competences. Technology design. Publishing House «Education», 5, 61.

Ibragimov, G. I. (2011). Innovative learning technologies in the conditions of implementation of the competency approach. Journal of Innovations in Education, 4, 4.

Isaev, J. F. (2008). The development of professional pedagogical culture under conditions of continuous education. Collective monograph Belgorod, 213

Kirilova, G. I. (2008). Principles of information and environmental approach to the modernization of vocational training. Kazan pedagogical journal, 8, 98.

Krechetnikov, K. G. (2002). Designing creative educational environment on the basis of information technology at the university. Monograph. Publishing House of Goskoortsentr, 296.

Levina, E. Y. (2012). Control of education on the basis of quality management. Publishing House Fundamental research, 11, 571.

Moiseeva, N. N. (1996). Ecology and education Publishing. House of Leningrad. University, 220.

Mukhametzyanova, G. V. (2010). New Paradigms of Education in training competent professionals.Bulletin of the Moscow State Regional University. Publishing House «Psychological Science», 127.

Novikov, A. M. (2006). Introduction to the methodology of game activity. Publisher House «Egves», 48.

Prokofeva, E. N. (2012). Integrative play in the formation of professional competencies in undergraduate Profile Protection in emergency situations. Kazan pedagogical journal, 4, 55.

Robert, I. V. (1994). Modern information technologies in education: didactic problems and prospects of Use. Publisher House «School Press», 205.

Selevko, G. K. (1998). Modern educational technology. Publisher House Education, 58.

Subetto, A. I. (2000). Kvalitologiya education. Moscow Centre Publisher, 220.

Traynev, V. A. (2006). Information and communication technology teaching (generalizations and recommendations). Publishing and Trading Corporation Dashkov \& Co, 280.

Zaynutdinova, L. H. (1999). Creation and use of electronic textbooks (for example, technical disciplines). Monograph. Astrakhan. Publishing House Ltd. TSITEP, 326.

Zeer, E. F. (2005). The modernization of vocational education: competence approach. Moscow Publisher, 216.

Zimnya, I. A. (2006). Competence approach. What is its place in the modern approaches to education? (Theoretical and methodological aspect). Journal of Higher education today, 8, 29.

\section{Copyrights}

Copyright for this article is retained by the author(s), with first publication rights granted to the journal.

This is an open-access article distributed under the terms and conditions of the Creative Commons Attribution license (http://creativecommons.org/licenses/by/3.0/). 